\title{
16S Metagenomics of Nitrifying Bacteria and Archaea Inhabiting Maize Rhizosphere and the Influencing Environmental Factors
}

\author{
Oluwatobi Esther Ayiti \\ North-West University \\ Ayansina Segun Ayangbenro \\ North-West University \\ Olubukola Oluranti Babalola ( $\sim$ olubukola.babalola@nwu.ac.za ) \\ North-West University https://orcid.org/0000-0003-4344-1909
}

\section{Research Article}

Keywords: Nitrospirae, biotechnology, nitrate, maize growth stages, nucleospin, ammonia

Posted Date: November 2nd, 2021

DOI: https://doi.org/10.21203/rs.3.rs-1010152/v1

License: (c) (i) This work is licensed under a Creative Commons Attribution 4.0 International License. Read Full License 


\section{Abstract}

The maize rhizosphere soil is unique with diverse microorganisms. Nitrifying bacteria and archaea are ubiquitous and can transform ammonia locked up in soil or manure into nitrate; a more soluble form of nitrogen. However, nitrifying bacteria and archaea inhabiting maize rhizosphere are yet to be identified. We elucidate the diversity and abundance of nitrifying bacteria and archaea associated with maize rhizosphere across different growth stages using $16 \mathrm{~S}$ metagenomics sequencing. Also, the influence of environmental factors on the nitrifying communities was evaluated. The maize rhizosphere soil was collected from North-West University, Molelwane, South Africa. DNA was extracted using Nucleospin Soil DNA extraction kit and the V3-V4 hypervariable region was sequenced on Illumina Miseq platform. MG-RAST was used to analyze the raw sequences. The environmental factors were measured using standard procedure. The result revealed 9 genera of nitrifying bacteria; Nitrospira, Nitrosospira, Nitrobacter, Nitrosovibrio, Nitrosomonas, Nitrosococcus, Nitrococcus, unclassified (derived from Nitrosomonadales), unclassified (derived from Nitrosomonadaceae) and 1 archaeon Candidatus Nitrososphaera. The Nitrospirae phyla group which had the most nitrifying bacteria was more abundant at the tasselling stage (67.94\%). Alpha diversity showed no significant difference. However, the Beta diversity showed significant difference $(P=0.01, R=0.58)$ across the growth stages. The growth stages had no significant effect on the diversity of nitrifying bacteria and archaea, but the tasselling stage had the most abundant. A correlation was observed among some of the environmental factors. The research outcome can be put into consideration while carrying out a biotechnological process that involves nitrifying bacteria and archaea.

\subsection{Introduction}

Metagenomics has exposed an extraordinary degree of diversity and novelty among microbial communities. Its analysis can involve sequence-based or functional approaches or a combination of both. It could help the development of management practices that maximize the beneficial use of microbial communities in and around the crops. Also, it could lead to the discovery of novel natural products, new antibiotics, new bioactive molecules and new functions. Pyrosequencing of bacterial $16 \mathrm{~S}$ genes has led to observed substantial variation in bacterial richness, diversity, and relative abundances of taxa between bulk soil and the maize rhizosphere, as well as between fields [1]. Molecular case finding, characterization, surveillance of microorganisms and rapid identification of bacteria can be achieved using the 16S rRNA region [2]. Also, comparing 16S sequence profiles across samples clarifies how microbial diversity is associated with environmental conditions [3].

Nitrifying bacteria and archaea are the microorganisms that carry out the biochemical reaction of transforming ammonia to nitrate. Their importance cannot be overemphasized because they help in the regulation of gene expression, mediate hormone signals [4] and are less acidic than ammonia. An acidic environment increases the bioavailability of heavy metals [5] and affects nutrient uptake [6]. The use of synthetic fertilizer [7] and nitrifying inhibitors [8] has been used to replace the function of these organisms. Unfortunately, this has caused an adverse environmental effect [7, 9]. A management process that would mimic the natural process would be better to achieve both agricultural intensification and environmental sustainability.

The rhizosphere serves as an interface that supports exchange of resources between plant and their associated soil environment. Its microbial diversity is influenced by physical, biological and chemical properties usually determined by the host plant. Microbes in the maize rhizosphere can be endophytic, epiphytic, or closely associated [1]. They can be diverse with various organisms, such as fungi, bacteria, archaea, nematodes and other invertebrates, due to the exudates (metabolite) secreted by the plant. The organisms either play a positive role by enhancing the growth of the plant or a negative role by causing disease. The composition of the microbial communities in rhizosphere soil is influenced by various environmental factors. Characterizing the ones associated with enhanced crop yield is an important first step towards understanding the role of the microbiota in soil fertility [10]. The structure and diversity of bacterial community in the rhizosphere vary significantly according to plant species [11]. This diversity is a result of differences in the type of exudates and signaling compounds they produce.

Substantial variation is being observed in the microbial diversity of maize rhizosphere. Their root exudate has some unique characteristics, which enable them to attract high diversity of microorganisms. It contains sugars, organic acids, aromatics and enzymes, which attract a wide range of microbial diversity [1]. Hence, their ability to thrive under unfavorable weather conditions. Evidence shows that the economic gains of farmers through maize production have led to an increased level of household food 
security primarily in relation to nutritional balance [12]. Maize is an important source of nutraceuticals, such as phenolics, carotenoids, anthocyanins, phlobaphenes, insoluble and soluble dietary fiber and polar and nonpolar lipids, which are known to prevent diseases and enhance health [13].

There exists a direct and indirect interlink within and between soil physical, chemical and biological parameters. The richness, diversity and structure of microbial communities can be affected by environmental parameters and edaphic properties, mainly $\mathrm{pH}$ and nutrients. Researchers have reported the relationship of $\mathrm{pH}$ with other soil parameters [14-16]. Organic carbon had a significant correlation with $\mathrm{pH}[14,15]$. A high level of sulfur in the soil increases its $\mathrm{pH}$ [16]. According to [17], nitrogen cycling is intimately linked to Sulphur and Carbon cycling. Plant yield, quality and growth are optimized when the ratio of ammonia to nitrate is low, Liu, Du and Li [18] suggested a ratio of (1:3). The ratio of carbon to nitrogen and soil total nitrogen influence both microbial activity and soil quality [14], this is pivotal to crop production.

One of the methods of biofertilization is increasing the abundance of microbes in the rhizosphere of plants [19]. Elucidating nitrifying bacteria and archaea associated with specific crop types and growth stages could provide information for its biotechnological application. To date, many of the maize rhizosphere resident nitrifying bacteria and archaea associated with varying growth stages are unknown. Identifying them and the influence of the rhizosphere environmental factors would enhance microbiome-based management strategy for nitrogen utilization. We hypothesize that maize rhizosphere inhabit unique composition of nitrifying bacteria and archaea across different growth stages and they are influenced by environmental factors. This study elucidates the diversity and abundance of nitrifying bacteria and archaea across different growth stages of maize rhizosphere using $16 \mathrm{~S}$ metagenomics. Also, the study evaluates the relationship among the environmental factors and their influence on the nitrifying bacteria and archaea.

\subsection{Materials And Method}

\subsection{Sampling and Environmental condition}

The samples were collected from the 32 years old maize plantation of the North-West University, Molelwane, Mahikeng, South Africa ( $25^{\circ} 47^{\prime} 23.9604^{\prime \prime} \mathrm{S}, 25^{\circ} 37^{\prime} 8.43348^{\prime \prime} \mathrm{E}$; altitude $1012 \mathrm{~m}$ Fig. 1). The region has a mean annual temperature ranging from $22^{\circ} \mathrm{C}-35^{\circ} \mathrm{C}$ in summer, $2^{\circ} \mathrm{C}-20^{\circ} \mathrm{C}$ in winter and an annual rainfall of $450 \mathrm{~mm}$. The farm was irrigated and treated with NPK $(20 \%$ Nitrogen, 7\% Phosphorus and 3\% Potassium) fertilizer before planting. The maize cultivar planted was QN.633. Three different growth stages of maize were identified; Pretasseling growth stage (PR), tasselling growth stage (TA) and fruiting growth stage (FR). The rhizosphere soil was collected between 0-15 cm depth and 0-5 cm breath of each maize root and bulk (BU) soil was also collected. The soil was collected in triplicate for each developmental stage and bulk soil, then transported to the laboratory and stored at $-20^{\circ} \mathrm{C}$.

\subsection{Physio-chemical analysis of the rhizosphere and bulk soil}

The physical and chemical properties of the soils were measured using standard chemical analysis. The particle size (sand, silt and clay) distribution was evaluated using the method of Kroetsch [20]. Nitrate and Ammonium were measured using KCL extraction method described by Keeny and Nelson [21]. Organic matter was measured using loss of ignition method [22]. Total carbon was analyzed using dry combustion method [23]. Organic carbon was measured using the method described by Walkley and Black [24]. Total Nitrogen was analyzed using digestion method [25]. HCl extraction method was used to determine the sulfur content of the rhizosphere as described by Smittenberg [26]. The pH was measured with Jenway $3520 \mathrm{pH}$ meter (cole parner instruments, Staffordshire UK) after mixing rhizosphere $(2 \mathrm{~g})$ and deionized water $(10 \mathrm{ml})$.

\subsection{DNA extraction and $16 \mathrm{~S}$ metagenomics sequencing}

DNA was extracted using a Nucleospin soil DNA extraction kit (Macherey-Nagel, Duren, Germany) following the manufacturer's instructions. The V3 - V4 hypervariable portions of the $16 \mathrm{~S}$ rRNA gene were targeted with universal primer pairs 341F (5'-CCT ACG GGN GGC WGC AG-3') and 785R (5'-GAC TAC HVG GGT ATC TAA TCC-3') [27]. The amplicons were then gel purified, end-repaired, and Illumina-specific adaptor sequences ligated to each of them. The samples were individually indexed after quantification, and 
another purification step was conducted. The amplicons were sequenced using a MiSeq v3 (600 cycles) kit on Illumina's MiSeq platform. For each experiment, $20 \mathrm{Mb}$ of data (2x300 bp long paired-end reads) was generated.

\subsection{Metagenome assembly and gene annotation}

The MG-RAST server (http://www.mg-rast.org) was used to process and analyze the raw sequences, which were uploaded as a FastQ file [28]. Trimomatic $v 0.33$ program was used to carry out the quality control which included filtering of ambiguous bases, removal of chimeras, minimum read specification and length filtering [29]. Following that, the sequence reads were annotated using the BLAT technique [30] and the M5NR database [31]. The data normalization tool was applied to reduce experimental error. Default parameters were used for the bioinformatics tools. The abundance of bacterial and archaeal community at different growth stages were evaluated. Reads of eukaryotes and unclassified sequences were removed.

\subsection{Data and statistical analysis}

Microsoft Excel software was used in evaluating the mean of the triplicate samples and the relative abundance of the Bacterial and Archaea diversity. The richness of the species sequence was evaluated through rarefactions analyses on MG RAST. Heat map of the relative abundance of bacteria and archaea was carried out using online software (www.heatmapper.ca/expression). Alpha and beta diversity was carried out using Past version 2.17 [32]. The CANOCO 5 was used to carry out principal component analysis and principal coordinate analysis using default settings [33]. XLSTAT was used to determine the relationship between the environmental factors and the influence on nitrifying bacteria and archaea.

\subsection{Results}

\subsection{Rhizosphere environmental factors}

The statistical analysis of the rhizosphere physical and chemical parameters are summarized in Table 1. The pH which is the focal point of the physical and chemical parameter ranges from 5.35 to 6.22 with a mean of 5.93 . The soil sample contained a mean of $85 \%$ sand, $13 \%$ clay, $0.73 \%$ organic carbon, $0.73 \%$ total carbon, $2.4 \%$ organic matter, $0.08 \%$ total nitrogen, $336.5 \mathrm{mg} / \mathrm{kg}$ sulphur, $4.348 \mathrm{mg} / \mathrm{kg}$ ammonium, $6.123 \mathrm{mg} / \mathrm{kg}$ nitrate. The carbon to nitrogen ratio is approximately 9:1. The $\mathrm{NH}_{4}$ to $\mathrm{NO}_{3}$ ratio is approximately 1:1.4.

Table 1

Physio-chemical parameters of the Maize rhizosphere.

\begin{tabular}{|c|c|c|c|c|}
\hline Variable & Minimum & Maximum & Mean & Std. deviation \\
\hline SA & 84.00 & 86.00 & 85.00 & 1.16 \\
\hline CL & 12.00 & 14.00 & 13.00 & 1.16 \\
\hline pH & 5.35 & 6.22 & 5.93 & 0.41 \\
\hline S & 246.00 & 576.00 & 336.50 & 159.85 \\
\hline OC & 0.52 & 0.84 & 0.73 & 0.15 \\
\hline TC & 0.52 & 0.89 & 0.73 & 0.15 \\
\hline OM & 2.04 & 2.70 & 2.43 & 0.30 \\
\hline TN & 0.06 & 0.09 & 0.08 & 0.01 \\
\hline $\mathrm{NH}_{4}$ & 3.84 & 4.67 & 4.35 & 0.40 \\
\hline $\mathrm{NO}_{3}$ & 4.02 & 9.76 & 6.12 & 2.72 \\
\hline
\end{tabular}




\subsection{S metagenomics sequencing of maize rhizosphere across different growth stages}

The information of the sequence read is listed in Table 2. Rarefraction curve shows the richness of species sequences across the different vegetative growth (Fig. 2). Table 3 and Fig. 3 show the bacteria and archaea phylum relative abundance represented in all growth stages. Over $99 \%$ of the reads were predominantly bacteria, while the archaea were less than $1 \%$. Phylum Actinobacteria was the most dominant in all the growth stages and was highest (47\%) at PR. The BU showed the highest percentage of Proteobacteria (10.4\%) and Bacteroides (5.2\%). Gemmatimonadates (5.6\%) and Chloroflex (2.6\%) were highest at PR. At TA, Planctomycete and Acidobacteria were highest at $6.5 \%$ and $7.8 \%$ respectively. Phylum Firmicutes was highest (27\%) at FR. Thaumarchaeota was the only phylum observed in the archaea domain. Although it was less than $1 \%$ in all the stages, it was highest at the FR. There was no significant difference $(P=0.99)$ in the bacteria and archaea phylum groups across the different growth stages (Table 4). At $P=0.01, R=0.58$ the beta diversity showed a significant difference across the growth stages.

Table 2

16S Metagenomic sequence information for maize rhizosphere across different growth stages

\begin{tabular}{|c|c|c|c|c|c|c|c|c|c|}
\hline \multirow[t]{2}{*}{ SAMPLE } & \multicolumn{5}{|c|}{ DATA BEFORE QC } & \multicolumn{4}{|c|}{ DATA AFTER QC } \\
\hline & Size (bp) & $\begin{array}{l}\text { No. of } \\
\text { raw } \\
\text { sequence } \\
\text { reads }\end{array}$ & $\begin{array}{l}\text { Mean } \\
\text { sequence } \\
\text { length(bp) }\end{array}$ & $\begin{array}{l}\text { Mean GC } \\
\text { content(\%) }\end{array}$ & $\begin{array}{l}\text { No of } \\
\text { artificial } \\
\text { duplicate } \\
\text { read }\end{array}$ & Size (bp) & $\begin{array}{l}\text { No. of } \\
\text { sequence } \\
\text { reads }\end{array}$ & $\begin{array}{l}\text { Mean } \\
\text { sequence } \\
\text { length } \\
\text { (bp) }\end{array}$ & $\begin{array}{l}\text { Mean } \\
\text { GC } \\
\text { content } \\
(\%)\end{array}$ \\
\hline BU1 & 39999874 & 93132 & $429 \pm 60$ & $59 \pm 5$ & 78725 & 5544447 & 13981 & $397 \pm 92$ & $59 \pm 4$ \\
\hline BU2 & 33959250 & 79190 & $429 \pm 62$ & $58 \pm 5$ & 66328 & 4922216 & 12368 & $398 \pm 91$ & $59 \pm 4$ \\
\hline BU3 & 39439263 & 91569 & $431 \pm 59$ & $58 \pm 4$ & 78070 & 5209032 & 13189 & $395 \pm 94$ & $58 \pm 4$ \\
\hline PR1 & 34765082 & 81200 & $428 \pm 61$ & $59 \pm 4$ & 68091 & 5073152 & 12759 & $398 \pm 91$ & $59 \pm 4$ \\
\hline PR2 & 33890551 & 78866 & $430 \pm 57$ & $59 \pm 4$ & 66470 & 4840435 & 12182 & $397 \pm 91$ & $59 \pm 4$ \\
\hline PR3 & 45088395 & 104815 & $430 \pm 60$ & $58 \pm 5$ & 89330 & 5962707 & 14913 & $400 \pm 88$ & $59 \pm 4$ \\
\hline TA1 & 39088384 & 91384 & $428 \pm 60$ & $58 \pm 5$ & 77224 & 5387058 & 13644 & $395 \pm 91$ & $59 \pm 4$ \\
\hline TA2 & 37052055 & 87143 & $425 \pm 69$ & $58 \pm 7$ & 73348 & 5025426 & 12809 & $392 \pm 94$ & $59 \pm 4$ \\
\hline TA3 & 31458263 & 74393 & $423 \pm 67$ & $58 \pm 6$ & 61962 & 4557768 & 11824 & $385 \pm 95$ & $59 \pm 4$ \\
\hline FR1 & 35728655 & 84510 & $423 \pm 66$ & $58 \pm 5$ & 69749 & 5486405 & 14237 & $385 \pm 95$ & $58 \pm 4$ \\
\hline FR2 & 34499959 & 81697 & $422 \pm 68$ & $58 \pm 6$ & 66905 & 5381358 & 14139 & $\begin{array}{l}381 \pm \\
100\end{array}$ & $58 \pm 5$ \\
\hline FR3 & 33357878 & 78587 & $424 \pm 64$ & $58 \pm 5$ & 65154 & 5088829 & 13101 & $388 \pm 95$ & $59 \pm 4$ \\
\hline
\end{tabular}


Table 3

Relative abundance (\%) of the different phylum across the different growth stages

\begin{tabular}{|c|c|c|c|c|}
\hline Phylum & BU & PR & TA & FR \\
\hline Actinobacteria & $46.053 \pm 3.137$ & $46.988 \pm 3.377$ & $41.997 \pm 2.371$ & $42.016 \pm 2.183$ \\
\hline Firmicutes & $23.800 \pm 4.266$ & $24.171 \pm 2.097$ & $24.902 \pm 4.510$ & $26.752 \pm 0.835$ \\
\hline Proteobacteria & $10.350 \pm 0.857$ & $9.210 \pm 0.468$ & $9.861 \pm 0.797$ & $10.066 \pm 1.395$ \\
\hline Gemmatimonadetes & $4.920 \pm 0.152$ & $5.589 \pm 0.651$ & $3.664 \pm 1.025$ & $5.164 \pm 0.444$ \\
\hline Planctomycetes & $3.600 \pm 0.609$ & $4.334 \pm 0.795$ & $6.452 \pm 1.192$ & $4.551 \pm 0.484$ \\
\hline Chloroflexi & $2.256 \pm 0.450$ & $2.592 \pm 0.418$ & $1.527 \pm 0.034$ & $2.026 \pm 0.363$ \\
\hline Acidobacteria & $2.099 \pm 0.309$ & $2.912 \pm 0.726$ & $7.837 \pm 2.114$ & $4.226 \pm 1.271$ \\
\hline Bacteroidetes & $5.232 \pm 6.370$ & $2.215 \pm 0.352$ & $1.405 \pm 0.094$ & $2.322 \pm 0.289$ \\
\hline Verrucomicrobia & $0.606 \pm 0.128$ & $0.853 \pm 0.141$ & $0.842 \pm 0.111$ & $1.476 \pm 0.068$ \\
\hline Nitrospirae & $0.401 \pm 0.036$ & $0.414 \pm 0.086$ & $0.698 \pm 0.305$ & $0.500 \pm 0.021$ \\
\hline Cyanobacteria & $0.250 \pm 0.090$ & $0.268 \pm 0.070$ & $0.107 \pm 0.035$ & $0.220 \pm 0.068$ \\
\hline Spirochaetes & $0.176 \pm 0.067$ & $0.194 \pm 0.041$ & $0.366 \pm 0.309$ & $0.400 \pm 0.096$ \\
\hline Deinococcus-Thermus & $0.123 \pm 0.067$ & $0.104 \pm 0.020$ & $0.035 \pm 0.012$ & $0.079 \pm 0.011$ \\
\hline Chlamydiae & $0.040 \pm 0.018$ & $0.041 \pm 0.014$ & $0.055 \pm 0.015$ & $0.075 \pm 0.043$ \\
\hline Thermotogae & $0.038 \pm 0.003$ & $0.050 \pm 0.014$ & $0.178 \pm 0.018$ & $0.073 \pm 0.005$ \\
\hline Thermodesulfobacteria & $0.010 \pm 0.009$ & $0.008 \pm 0.004$ & $0.004 \pm 0.004$ & $0.008 \pm 0.003$ \\
\hline Aquificae & $0.015 \pm 0.003$ & $0.016 \pm 0.004$ & $0.019 \pm 0.004$ & $0.011 \pm 0.002$ \\
\hline Tenericutes & $0.009 \pm 0.005$ & $0.0188 \pm 0.005$ & $0.001 \pm 0.001$ & $0.006 \pm 0.003$ \\
\hline Synergistetes & $0.013 \pm 0.004$ & $0.010 \pm 0.003$ & $0.032 \pm 0.019$ & $0.018 \pm 0.003$ \\
\hline Dictyoglomi & $0.004 \pm 0.002$ & $0.008 \pm 0.008$ & $0.009 \pm 0.005$ & $0.004 \pm 0.002$ \\
\hline Deferribacteres & $0.002 \pm 0.002$ & $0.001 \pm 0.001$ & $0.003 \pm 0.001$ & $0.002 \pm 0.000$ \\
\hline Chlorobi & $0.001 \pm 0.001$ & $0.002 \pm 0.001$ & $0.004 \pm 0.002$ & $0.002 \pm 0.002$ \\
\hline Elusimicrobia & $0.001 \pm 0.001$ & $0.002 \pm 0.002$ & $0.002 \pm 0.002$ & $0.001 \pm 0.002$ \\
\hline Fibrobacteres & $0.001 \pm 0.001$ & $0.000 \pm 0.000$ & $0.000 \pm 0.000$ & $0.002 \pm 0.002$ \\
\hline Thaumarchaeota & $0.001 \pm 0.001$ & $0.003 \pm 0.002$ & $0.002 \pm 0.002$ & $0.004 \pm 0.003$ \\
\hline
\end{tabular}


Evaluation of evenness and diversity of bacteria and archaea across different growth stages.

\begin{tabular}{|llllll|}
\hline Diversity indices & BU & PR & TA & FR & P-value \\
\hline Phylum & & & & & \\
Simpson_1-D & $0.71 \pm 0.06$ & $0.71 \pm 0.07$ & $0.74 \pm 0.07$ & $0.73 \pm 0.06$ & 0.99 \\
\hline Shannon_H & $1.62 \pm 0.19$ & $1.61 \pm 0.18$ & $1.69 \pm 0.19$ & $1.69 \pm 0.19$ & \\
\hline Evenness_e $\mathrm{H} / \mathrm{S}$ & $0.20 \pm 0.10$ & $0.21 \pm 0.11$ & $0.23 \pm 0.10$ & $0.22 \pm 0.11$ & \\
\hline The P-value is based on Kruskal-wallis. Mean \pm standard error $(\mathrm{n}=3)$. & \\
\hline
\end{tabular}

\subsection{Taxonomic profiling of nitrifying bacteria and archaea inhabiting maize rhizosphere across different vegetative growth stages}

At the genus level, 9 groups of nitrifying bacteria and 1 group of archaea were identified (Table 5 and Fig. 4). Nitrospira groups are the most abundant with their relative abundance highest at the TA stage 67.94\%. Nitrosospira and unclassified (derived from Nitrosomonadales and Nitrosomonadaceae) were also notably abundant. Fig. 5. shows the principal component analysis (PCA) conducted to reveal how the nitrifying bacteria and archaea were distributed at the various growth stages.

Table 5

Relative abundance (\%) of nitrifying bacteria and archaea at genus level at the different growth stages

\begin{tabular}{|lllll|}
\hline Genus & BU & PR & TA & FR \\
\hline Nitrospira & $66.82 \pm 5.34$ & $65.20 \pm 2.27$ & $67.94 \pm 7.85$ & $63.6 \pm 2.22$ \\
\hline Nitrosospira & $12.56 \pm 1.14$ & $13.30 \pm 0.38$ & $9.67 \pm 4.03$ & $11.62 \pm 1.47$ \\
\hline unclassified (derived from Nitrosomonadales) & $12.10 \pm 3.18$ & $11.75 \pm 1.64$ & $14.50 \pm 1.73$ & $15.54 \pm 2.95$ \\
\hline unclassified (derived from Nitrosomonadaceae) & $2.67 \pm 1.43$ & $2.63 \pm 0.32$ & $0.89 \pm 0.58$ & $1.77 \pm 0.14$ \\
\hline Nitrobacter & $2.10 \pm 0.90$ & $2.49 \pm 1.22$ & $3.81 \pm 2.22$ & $3.28 \pm 0.40$ \\
\hline Nitrosovibrio & $2.01 \pm 0.26$ & $2.20 \pm 0.81$ & $1.65 \pm 0.18$ & $1.52 \pm 0.30$ \\
\hline Nitrosomonas & $1.12 \pm 0.59$ & $0.87 \pm 0.49$ & $0.43 \pm 0.13$ & $1.10 \pm 0.50$ \\
\hline Candidatus Nitrososphaera & $0.18 \pm 0.16$ & $0.42 \pm 0.37$ & $0.17 \pm 0.15$ & $0.56 \pm 0.35$ \\
\hline Nitrosococcus & $0.17 \pm 0.29$ & $0.00 \pm 0.00$ & $0.37 \pm 0.37$ & $0.63 \pm 0.47$ \\
\hline \begin{tabular}{l} 
Nitrococcus \\
BU- Bulk soil, PR- Pretasseling stage rhizosphere, TA- Tasseling stage rhizosphere, FR- Fruiting stage rhizosphere. Mean \pm \\
\hline standard deviation (n=3).
\end{tabular} & & & & $0.08 \pm 0.13$ \\
\hline
\end{tabular}

\subsection{Assessment of nitrifying bacteria and archaea diversity across different growth stages.}

The diversity indices, Simpson, Shannon and Evenness, were used to evaluate alpha diversity of nitrifying bacteria and archaea across different groups. At $P=0.99$ the different genera groups showed no significant difference (Table 6). Beta diversity showed a significant difference $(P=0.01 ; R=0.58)$ among the genera across the different growth stages. Principal coordinate analysis (PCoA) showed a distinct diversity exists across the different growth stages (Fig. 6). 
Alpha diversity evaluation of nitrifying bacteria and archaea across different growth stages.

\begin{tabular}{|llllll|}
\hline Diversity indices & BU & PR & TA & FR & P-value \\
\hline Genus & & & & & \\
Simpson_1-D & $0.52 \pm 0.07$ & $0.54 \pm 0.11$ & $0.51 \pm 0.10$ & $0.56 \pm 0.10$ & 0.99 \\
\hline Shannon_H & $1.13 \pm 0.19$ & $1.19 \pm 0.22$ & $1.09 \pm 0.20$ & $1.21 \pm 0.21$ & \\
\hline Evenness_e^H/S & $0.31 \pm 0.10$ & $0.33 \pm 0.13$ & $0.27 \pm 0.12$ & $0.28 \pm 0.12$ & \\
\hline The P-values are based on Kruskal-wallis. Mean \pm standard error $(\mathrm{n}=3)$. & \\
\hline
\end{tabular}

\subsection{Relationship among maize rhizosphere environmental factors and their influence on nitrifying microorganism}

The Pearson's correlation coefficient showed both positive and negative correlation among the physical and chemical parameters (Table 7).

Table 7

Pearson's correlation coefficient ( $r$ ) matrix analysis showing relationship among maize rhizosphere environmental factors.

\begin{tabular}{|c|c|c|c|c|c|c|c|c|c|c|c|}
\hline Variables & SA & $\mathrm{CL}$ & $\mathrm{pH}$ & $S$ & $O C$ & $\mathrm{TC}$ & $\mathrm{OM}$ & $\mathrm{TN}$ & $\mathrm{NH} 4$ & NO3 & NB \\
\hline SA & 1 & & & & & & & & & & \\
\hline $\mathrm{CL}$ & -1.00 & 1 & & & & & & & & & \\
\hline $\mathrm{pH}$ & -0.81 & 0.81 & 1 & & & & & & & & \\
\hline$S$ & -0.60 & 0.60 & 0.51 & 1 & & & & & & & \\
\hline$O C$ & -0.84 & 0.84 & 0.10 & 0.54 & 1 & & & & & & \\
\hline $\mathrm{TC}$ & -0.81 & 0.81 & 0.98 & 0.34 & 0.97 & 1 & & & & & \\
\hline $\mathrm{OM}$ & -0.91 & 0.91 & 0.97 & 0.65 & 0.98 & 0.94 & 1 & & & & \\
\hline TN & -0.74 & 0.74 & 0.98 & 0.62 & 0.98 & 0.91 & 0.95 & 1 & & & \\
\hline NH4 & 0.27 & -0.27 & 0.06 & 0.53 & 0.06 & -0.13 & 0.04 & 0.27 & 1 & & \\
\hline NO3 & -0.88 & 0.88 & 0.72 & 0.90 & 0.76 & 0.62 & 0.86 & 0.75 & 0.16 & 1 & \\
\hline NB & 0.22 & -0.22 & -0.59 & 0.38 & -0.55 & -0.71 & -0.41 & -0.49 & 0.31 & 0.12 & 1 \\
\hline \multicolumn{12}{|c|}{$\begin{array}{l}\text { Abbreviation of parameters are detailed in Table } 1 . r ; 0.90 \text { to } 1.00(-0.90 \text { to }-1.00)=\text { very highly positive (negative) correlation } \\
\text { r; } 0.70 \text { to } 0.90(-0.70 \text { to }-0.90)=\text { highly positive (negative) correlation. } r ; 0.50 \text { to } 0.70(-0.50 \text { to }-0.70)=\text { Moderately positive } \\
\text { (negative) correlation. } r ; 0.30 \text { to } 0.50(-0.30 \text { to }-0.50)=\text { Low positive (negative) correlation. } r ; 0.00 \text { to } 0.30(-0.00 \text { to }-0.30)= \\
\text { insignificant correlation. } p \leq 0.05\end{array}$} \\
\hline
\end{tabular}

\subsection{Influence of maize rhizosphere environmental factors on nitrifying bacteria and archaea}

Table 8. showed that a substantial number of the environmental factors had both positive and negative correlations on the nitrifying community. 
Table 8

Pearson's correlation coefficient ( $r$ ) matrix analysis showing the influence of environmental factors and nitrifying bacteria.

\begin{tabular}{|c|c|c|c|c|c|c|c|c|c|c|}
\hline Variables & SA & $\mathrm{CL}$ & $\mathrm{pH}$ & $S$ & $\mathrm{OC}$ & $\mathrm{TC}$ & $\mathrm{OM}$ & TN & $\mathrm{NH} 4$ & NO3 \\
\hline Nitrospira & -0.07 & 0.07 & -0.49 & 0.29 & -0.44 & -0.53 & -0.28 & -0.49 & -0.16 & 0.22 \\
\hline Nitrosospira & -0.84 & 0.84 & 0.98 & 0.37 & 0.97 & 1.00 & 0.95 & 0.91 & -0.15 & 0.66 \\
\hline $\begin{array}{l}\text { unclassified (derived from } \\
\text { Nitrosomonadales) }\end{array}$ & 0.97 & -0.97 & -0.65 & -0.51 & -0.68 & -0.67 & -0.78 & -0.55 & 0.43 & -0.82 \\
\hline $\begin{array}{l}\text { unclassified (derived from } \\
\text { Nitrosomonadaceae) }\end{array}$ & -0.90 & 0.90 & 0.98 & 0.57 & 0.99 & 0.96 & 1.00 & 0.95 & -0.02 & 0.81 \\
\hline Nitrobacter & 0.94 & -0.94 & -0.92 & -0.74 & -0.94 & -0.87 & -0.99 & -0.91 & -0.06 & -0.93 \\
\hline Nitrosovibrio & -0.95 & 0.95 & 0.67 & 0.37 & 0.70 & 0.73 & 0.77 & 0.54 & -0.54 & 0.73 \\
\hline Nitrosomonas & -0.41 & 0.41 & 0.84 & 0.54 & 0.82 & 0.74 & 0.76 & 0.92 & 0.56 & 0.52 \\
\hline Candidatus Nitrososphaera & 0.20 & -0.20 & 0.33 & -0.50 & 0.28 & 0.41 & 0.11 & 0.30 & 0.01 & -0.41 \\
\hline Nitrosococcus & 0.88 & -0.88 & -0.49 & -0.31 & -0.52 & -0.55 & -0.61 & -0.35 & 0.63 & -0.66 \\
\hline Nitrococcus & 0.86 & -0.86 & -1.00 & -0.53 & -1.00 & -0.98 & -0.99 & -0.97 & -0.01 & -0.76 \\
\hline \multicolumn{11}{|c|}{$\begin{array}{l}\text { Abbreviation of parameters are detailed in Table } 1 . r ; 0.90 \text { to } 1.00(-0.90 \text { to }-1.00)=\text { very highly positive (negative) correlation. } \\
\text { r; } 0.70 \text { to } 0.90(-0.70 \text { to }-0.90)=\text { highly positive (negative) correlation. } r ; 0.50 \text { to } 0.70(-0.50 \text { to }-0.70)=\text { Moderately positive } \\
\text { (negative) correlation. } r ; 0.30 \text { to } 0.50(-0.30 \text { to }-0.50)=\text { Low positive (negative) correlation. } r ; 0.00 \text { to } 0.30(-0.00 \text { to }-0.30)= \\
\text { insignificant correlation. } p \leq 0.05\end{array}$} \\
\hline
\end{tabular}

\subsection{Discussion}

This study profiled the nitrifying bacteria and archaea associated with maize rhizosphere and evaluated their diversity across different growth stages. Also, the environmental factors were analyzed and correlated with the nitrifying community. The $\mathrm{pH}$ is seen to be moderately acidic (5.93) according to USDA [34] characterization. This could be as a result of the high level of sulfur noted $(336 \mathrm{mg} / \mathrm{kg})$. Sulfur is said to increase the acidity of soil when at a high level [35]. The ratio of Carbon to nitrogen (9:1) is slightly higher than USDA [34] recommendation (8:1). Also, the $\mathrm{NH}_{4}$ to $\mathrm{NO}_{3}$ ratio (1:1.4) falls short of expectation, Liu, Du and $\mathrm{Li}$ [18] reported a ratio of 1:3 for the soil microorganism. The holistic physical and chemical parameter does not seem to be favorable to the proliferation of nitrifying community with an average of $0.5 \%$ relative abundance (Table 3 ). Kong, Eriksen and Petersen [36] report a favorable $\mathrm{pH}$ of 7.0 to 7.5 for nitrifying bacteria.

Nitrifying bacteria and archaea are ubiquitous and are found in varying environmental conditions. The 9 genera of nitrifying bacteria identified in this study are; Nitrospira, Nitrosospira, unclassified (derived from Nitrosomonadales), unclassified (derived from Nitrosomonadaceae), Nitrobacter, Nitrosovibrio, Nitrosomonas, Nitrosococcus, Nitrococcus. The order Nitrosomonadaceae and Nitrosomonadales still have unclassified and yet to be cultured bacterium species that are likely to be nitrifying bacteria. The only archaea genus discovered was Candidatus Nitrososphaera, which carry out ammonia oxidation [37], it had also been reported by Melnichuk, Abdurashytov, Andronov, Abdurashytova, Egovtseva, Gongalo, Turin and Pashtetskiy [38] and Enebe and Babalola [39] to be associated with crops including maize.

Ammonia oxidizing bacteria noted in this study were Nitrosospira, Nitrosomonas, Nitrosococcus [40] and Nitrosovibrio [41]. Nitrosomonas was recently discovered in maize rhizosphere soil in low abundance by Wang, Rogers, $\mathrm{Ng}$ and $\mathrm{He}$ [42]. The nitrite oxidizing bacteria carrying out the second stage of nitrification were the genus Nitrospira, Nitrobacter and Nitrococcus [40]. Nitrospira is known to be well distributed globally and was found to be most abundant. It was recently observed by Sun, Zhao, Fan, Chen, Ruan and Wang [43] in a maize rhizosphere. Also, Nitrobacter was noted in a maize-soybean rotation system by Meier, Lopez-Guerrero, Guo, Schmer, Herr, Schnable, Alfano and Yang [44]. Unclassified nitrifying microorganisms were seen in the order Nitrosomonadaceae and order Nitrosomonadales. This affirms the possible presence of novel nitrifying bacteria in the studied maize rhizosphere. Stein [45], mentioned there has been an increasing number of novel nitrifying microorganisms discovered lately. This could be as a result of advanced technologies used in sequencing. 
Schlemper, Leite, Lucheta, Shimels, Bouwmeester, van Veen and Kuramae [46] affirm the existence of variation in bacteria population across different growth stages. The rarefraction curve shows that each of the growth stages had high number of species diversity (Fig. 2.). The PCoA plot showed a distinct diversity and gap across the growth stages (Fig. 6). The phylum Nitrospirae which had the most abundant nitrifying bacteria showed an increase from the BU to the TA and a decrease at the FR (Table 3). Also, Nitrospira genus was most abundant at the TA stage. This could be as a result of increasing demand of nutrient as the plant increase in growth. According to Rocha, Kuramae, Borges, Leite and Rosolem [47], the abundance of microorganisms associated with nitrification increases with increasing developmental stages. Furthermore, Lu et al. (2018) explain that the increased and prolonged availability of nitrogen in the rhizosphere by nitrifying microorganisms delays flowering.

The heatmap showed that all the nitrifying bacteria genus were unequally distributed across the different growth stages (Fig. 5). A likely trend was observed in the overall microbial community of a study carried out by Fu, Xiao, Liu, Zhang, Wang and Yang [48] at varying maize growth stages. This would probably be due to the varying composition of nutrients at the different growth stages. Although, the alpha diversity showed no significant difference. However, there was a significant difference $(P=0.01)$ in the beta diversity of the different growth stages. Peiffer et al. (2013), also reported a significant difference between the beta diversity between maize bulk soil and rhizosphere soil. They attributed it to the maize genotype. The result obtained from the correlation affirms there is indeed a direct and indirect interlink within the environmental factors. Also, between them and the nitrifying community, the environmental factors showed both positive and negative correlations with a substantial number of the nitrifying community. This was also observed by Fu, Xiao, Liu, Zhang, Wang and Yang [48] between microbial community and soil nutrients.

\subsection{Conclusion}

Profiling and diversity of nitrifying bacteria and archaea of maize rhizosphere across different growth stages were carried out. At the genus level, 9 genera of nitrifying bacteria and 1 archaeon were identified. 2 out of the 9 genera were yet to be identified nitrifying bacteria from the order Nitrosomonadaceae and order Nitrosomonadales. The tasselling growth stage had the most abundant of the nitrifying bacteria. The correlation within the environmental factors show the existence of a relationship between some parameter in the rhizosphere and it reveals possible impact or non-impact on nitrifying community. Prominent nitrifying bacteria and archaea associated with maize rhizosphere identified in this study and the understanding of the environmental factors influence on them can be used as a microbiome-based strategy to improve the productivity and yield of maize plants.

\section{Declarations}

Author Contributions: O.E.A. experimented and wrote the first draft of the paper, A.S.A critiqued and reviewed the manuscript, while O.O.B provided academic input and proofread the article.

Ethical Approval: This article does not contain any studies with human participants or animals.

Consent for publication: All authors approves the manuscript for publication

Funding: The study was funded by the National Research Foundation of South

Africa through 0.O.B. from the grant (UID 123634, UID 132595).

Conflicts of Interest: The authors declare no conflict of interest.

Data availability. The raw $16 \mathrm{~S}$ sequencing data for maize rhizosphere were deposited at the NCBI sequence read archive (SRA) with accession numbers. SRR14978863 (1st replication of bulk rhizosphere), SRR14978852 (2nd replication of bulk rhizosphere), SRR14978855 (3rd replication of bulk rhizosphere), SRR14978856 (1st replication of pretasseling rhizosphere), SRR14978857 (2nd replication of pretasseling rhizosphere), SRR14978858 (3rd replication of pretasseling rhizosphere), SRR14978859 (1st replication of tasseling rhizosphere), SRR14978860 
(2nd replication of tasseling rhizosphere), SRR14978861 (3rd replication of tasseling rhizosphere), SRR14978862 (1st replication of fruiting rhizosphere), SRR14978853

(2nd replication of fruiting rhizosphere), SRR14978854 (3rd replication of fruiting rhizosphere). The BioProject number is PRJNA742235.

Acknowledgments: We are grateful to the National Research Foundation of South Africa for funding research in Babalola's lab (UID123634, UID132595). The North-West University has provided O.E.A. with a bursary and research support.

\section{References}

1. Peiffer JA, Spor A, Koren O, Jin Z, Tringe SG, Dangl JL, Buckler ES, Ley RE (2013) Diversity and heritability of the maize rhizosphere microbiome under field conditions. Proceedings of the National Academy of Sciences 110: 6548-6553. doi: https://doi.org/10.1073/pnas.1302837110

2. Deurenberg RH, Bathoorn E, Chlebowicz MA, Couto N, Ferdous M, García-Cobos S, Kooistra-Smid AM, Raangs EC, Rosema S, Veloo AC (2017) Application of next generation sequencing in clinical microbiology and infection prevention. Journal of biotechnology 243: 16-24. doi: https://doi.org/10.1016/j.jbiotec.2016.12.022

3. Sharpton TJ (2014) An introduction to the analysis of shotgun metagenomic data. Frontiers in plant science 5: 209. doi: https://doi.org/10.3389/fpls.2014.00209

4. Hachiya T, Sakakibara H (2016) Interactions between nitrate and ammonium in their uptake, allocation, assimilation, and signaling in plants. Journal of Experimental Botany 68: 2501-2512. doi: https://doi.org/10.1093/jxb/erw449

5. Ayangbenro AS, Olanrewaju OS, Babalola 00 (2018) Sulfate-reducing bacteria as an effective tool for sustainable acid mine bioremediation. Frontiers in Microbiology 9: 1-10. doi: https://doi.org/10.3389/fmicb.2018.01986

6. Shi R-y, Ni N, Nkoh JN, Li J-y, Xu R-k, Qian W (2019) Beneficial dual role of biochars in inhibiting soil acidification resulting from nitrification. Chemosphere 234: 43-51. doi: https://doi.org/10.1016/j.chemosphere.2019.06.030

7. Verma N, Chaudhary S, Goyal S (2018) Long Term Effects of Inorganic Fertilizers and Organic Amendments on Ammonification and Nitrification Activity of Soils under Cotton-Wheat Cropping System. Int J Curr Microbiol App Sci 7: 718724. doi: https://doi.org/10.20546/ijcmas.2018.704.080

8. Fan K, Weisenhorn P, Gilbert JA, Shi Y, Bai Y, Chu H (2018) Soil pH correlates with the co-occurrence and assemblage process of diazotrophic communities in rhizosphere and bulk soils of wheat fields. Soil Biology Biochemistry 121: 185-192.

9. Zhai Y, Zhao X, Teng Y, Li X, Zhang J, Wu J, Zuo R (2017) Groundwater nitrate pollution and human health risk assessment by using HHRA model in an agricultural area, NE China. Ecotoxicology and Environmental Safety 137: 130-142. doi: https://doi.org/10.1016/j.ecoenv.2016.11.010

10. Qiao C, Penton CR, Xiong W, Liu C, Wang R, Liu Z, Xu X, Li R, Shen Q (2019) Reshaping the rhizosphere microbiome by bioorganic amendment to enhance crop yield in a maize-cabbage rotation system. Applied Soil Ecology 142: 136-146. doi: https://doi.org/10.1016/j.apsoil.2019.04.014

11. López-Carmona DA, Alarcón A, Martínez-Romero E, Peña-Cabriales JJ, Larsen J (2019) Maize plant growth response to whole rhizosphere microbial communities in different mineral $\mathrm{N}$ and $\mathrm{P}$ fertilization scenarios. Rhizosphere 9: 38-46. doi: https://doi.org/10.1016/j.rhisph.2018.11.004

12. Chowdhury JA (2016) Impact of market oriented maize cash crop production on house-hold food security: Bangladesh perspective. BRAC University.

13. Ekpa O, Palacios-Rojas N, Kruseman G, Fogliano V, Linnemann AR (2018) Sub-Saharan African maize-based foods: Technological perspectives to increase the food and nutrition security impacts of maize breeding programmes. Global food security 17: 48-56.

14. Xiao D, Huang Y, Feng S, Ge Y, Zhang W, He X, Wang K (2018) Soil organic carbon mineralization with fresh organic substrate and inorganic carbon additions in a red soil is controlled by fungal diversity along a pH gradient. Geoderma 321 : 79-89. doi: https://doi.org/10.1016/j.geoderma.2018.02.003

Page $11 / 18$ 
15. Tu C, He T, Lu X, Luo Y, Smith $P$ (2018) Extent to which pH and topographic factors control soil organic carbon level in dry farming cropland soils of the mountainous region of Southwest China. Catena 163: 204-209. doi: https://doi.org/10.1016/j.catena.2017.12.028

16. Li X, Yu H, Sun X, Yang J, Wang D, Shen L, Pan Y, Wu Y, Wang Q, Zhao Y (2019) Effects of sulfur application on cadmium bioaccumulation in tobacco and its possible mechanisms of rhizospheric microorganisms. Journal of hazardous materials 368: 308-315. doi: https://doi.org/10.1016/j.jhazmat.2018.12.099

17. Kopáček J, Cosby BJ, Evans CD, Hruška J, Moldan F, Oulehle F, Šantrůčková H, Tahovská K, Wright RF (2013) Nitrogen, organic carbon and sulphur cycling in terrestrial ecosystems: linking nitrogen saturation to carbon limitation of soil microbial processes. Biogeochemistry 115: 33-51.

18. Liu G, Du Q, Li J (2017) Interactive effects of nitrate-ammonium ratios and temperatures on growth, photosynthesis, and nitrogen metabolism of tomato seedlings. Scientia Horticulturae 214: 41-50. doi: https://doi.org/10.1016/j.scienta.2016.09.006

19. Igiehon NO, Babalola $O O$ (2017) Biofertilizers and sustainable agriculture: exploring arbuscular mycorrhizal fungi. Applied microbiology and biotechnology 101: 4871-4881.

20. Kroetsch D, and Wang, C. (2008) Particle size distribution. Soil sampling and methods of analysis 2: 713-725.

21. Keeny DR, Nelson DW (1982) Nitrogen - inorganic forms, American Society of Soil Science Inc., Madison, WI, USA.

22. Nelson DW, Sommers LE (1996) Total carbon, organic carbon, and organic matter, American Societ of Agronomy, Madison WI., USA.

23. Santi C, Giacomo C, Luigi PDA (2006) Direct determination of organic carbon by dry combustion in soils with carbonates. Communications in soil science and plant analysis 37: 155-162.

24. Walkley A, Black IA (1934) An examination of the Degtjareff method for determining soil organic matter, and a proposed modification of the chromic acid titration method. . Soil Science 37: 29- 38.

25. Bremme JM, Mulvaney CS (1982) Total nitrogen, Agronomy Monograph No. 9, American Society of Agronomy, Madison, WI, USA.

26. Smittenberg J (1951) Rapid methods for determining different types of sulphur compounds in soil. Plant and Soil 3: 353360.

27. Thijs S, Op De Beeck M, Beckers B, Truyens S, Stevens V, Van Hamme JD, Weyens N, Vangronsveld J (2017) Comparative evaluation of four bacteria-specific primer pairs for 16S rRNA gene surveys. Frontiers in microbiology 8: 494. doi: https://doi.org/10.3389/fmicb.2017.00494

28. Meyer F PD, D'Souza M, Olson R, Glass EM, Kubal M, Paczian T, Rodriguez A, Stevens R, Wilke A, Wilkening J, Edwards RA (2008) The metagenomics RAST server-a public resource for the automatic phylogenetic and functional analysis of metagenomes. BMC Bioinformatics 9: 1-8. doi: https://doi.org/10.1186/1471-2105-9-386

29. Bolger AM LM, Usadel B (2014) Trimmomatic: a flexible trimmer for Illumina sequence data. Bioinformatics 30: 2114-2120. doi: https://doi.org/10.1093/bioinformatics/btu170

30. Kent W (2002) BLAT: the BLAST-like alignment tool. Genome Res 12: 656-664. doi: https://doi.org/10.1101/gr.229202.

31. Wilke A HT, Wilkening J, Field D, Glass EM, Kyrpides N, Mavrommatis K, Meyer F (2012) The M5nr: a novel non-redundant database containing protein sequences and annotations from multiple sources and associated tools. BMC Bioinformatics 13: 141. doi: https://doi.org/10.1186/1471-2105-13-141.

32. Hammer O, Harper DAT, Ryan PD (2001) Paleontological Statistics Software Package for Education and Data Analysis. . Palaentologia Electronica 4: 9. doi: http://folk.uio.no/ohammer/past

33. Cajo J.F, Ter Braak, Smilauer P (1997) Software for Multivariate Data Exploration, Testing, and Summarization Biometris, Wageningen Research Foundation, Wageningen University and Research. the Netherlands and Petr Smilauer, Czech Republic. . http://www.canoco5.com

34. USDA (2014) Soil Survey Laboratory Methods Manual. United State of Agriculture, Natural Resource Conservation Service

35. Wang Y, Li Q, Hui W, Shi J, Lin Q, Chen X, Chen Y (2008) Effect of sulphur on soil Cu/Zn availability and microbial community composition. Journal of hazardous materials 159: 385-389. doi: https://doi.org/10.1016/j.jhazmat.2008.02.029

Page 12/18 
36. Kong X, Eriksen J, Petersen SO (2018) Evaluation of the nitrification inhibitor 3,4-dimethylpyrazole phosphate (DMPP) for mitigating soil N2O emissions after grassland cultivation. Agriculture, Ecosystems \& Environment 259: 174-183. doi: https://doi.org/10.1016/j.agee.2018.02.029

37. Zhalnina KV, Dias R, Leonard MT, Quadros PDd, Camargo FAO, C.Drew J, Farmerie WG, Daroub SH, Triplett EW (2014) Genome Sequence of Candidatus Nitrososphaera evergladensis from Group 1.1b Enriched from Everglades Soil Reveals Novel Genomic Features of The Ammonia Oxidizing Archaea. PLoS ONE 9: e101648. doi: doi:10.1371/journal.pone.0101648

38. Melnichuk T, Abdurashytov S, Andronov E, Abdurashytova E, Egovtseva AY, Gongalo A, Turin E, Pashtetskiy V (2020) The taxonomic structure of southern chernozem at the genus level influenced by microbial preparations and farming systems. IOP Conference Series: Earth and Environmental Science, vol. 422. IOP Publishing, pp. 012101.

39. Enebe MC, Babalola 00 (2021) The Influence of Soil Fertilization on the Distribution and Diversity of Phosphorus Cycling Genes and Microbes Community of Maize Rhizosphere Using Shotgun Metagenomics. Genes 12: 1022. doi: https://doi.org/10.3390/genes12071022

40. Schaechter M (2009) Encyclopedia of microbiology. Academic Press

41. Fu Q, Xi R, Zhu J, Hu H, Xing Z, Zuo J (2020) The relative contribution of ammonia oxidizing bacteria and archaea to N2O emission from two paddy soils with different fertilizer N sources: A microcosm study. Geoderma 375: 114486.

42. Wang Q, Rogers MJ, Ng S, He J (2021) Fixed nitrogen removal mechanisms associated with sulfur cycling in tropical wetlands. Water Research 189: 116619.

43. Sun P, Zhao Z, Fan P, Chen W, Ruan Y, Wang Q (2021) Ammonia and Nitrite Oxidizing Bacteria are Dominant in Nitrification of Maize Rhizosphere Soil Following Combined Application of Biochar and Chemical Fertilizer Frontiers in Microbiology: 12. doi: https://doi.org/10.3389/fmicb.2021.715070

44. Meier MA, Lopez-Guerrero MG, Guo M, Schmer MR, Herr JR, Schnable JC, Alfano JR, Yang J (2021) Rhizosphere Microbiomes in a Historical Maize-Soybean Rotation System Respond to Host Species and Nitrogen Fertilization at the Genus and Subgenus Levels. Applied and Environmental Microbiology 87: e03132-03120. doi: https://doi.org/10.1080/03650340.2021.1890720

45. Stein LY (2019) Insights into the physiology of ammonia-oxidizing microorganisms. Current Opinion in Chemical Biology 49: 9-15. doi: https://doi.org/10.1016/j.cbpa.2018.09.003

46. Schlemper TR, Leite MF, Lucheta AR, Shimels M, Bouwmeester HJ, van Veen JA, Kuramae EE (2017) Rhizobacterial community structure differences among sorghum cultivars in different growth stages and soils. FEMS microbiology ecology 93.

47. Rocha KF, Kuramae EE, Borges BMF, Leite MFA, Rosolem CA (2020) Microbial N-cycling gene abundance is affected by cover crop specie and development stage in an integrated cropping system. Archives of Microbiology 202: 2005-2012.

48. Fu J, Xiao Y, Liu Z, Zhang Y, Wang Y, Yang K (2020) Trichoderma asperellum improves soil microenvironment in different growth stages and yield of maize in saline-alkaline soil of the Songnen Plain. Plant, Soil and Environment 66: 639-647. doi: https://doi.org/10.17221/456/2020-PSE

\section{Figures}



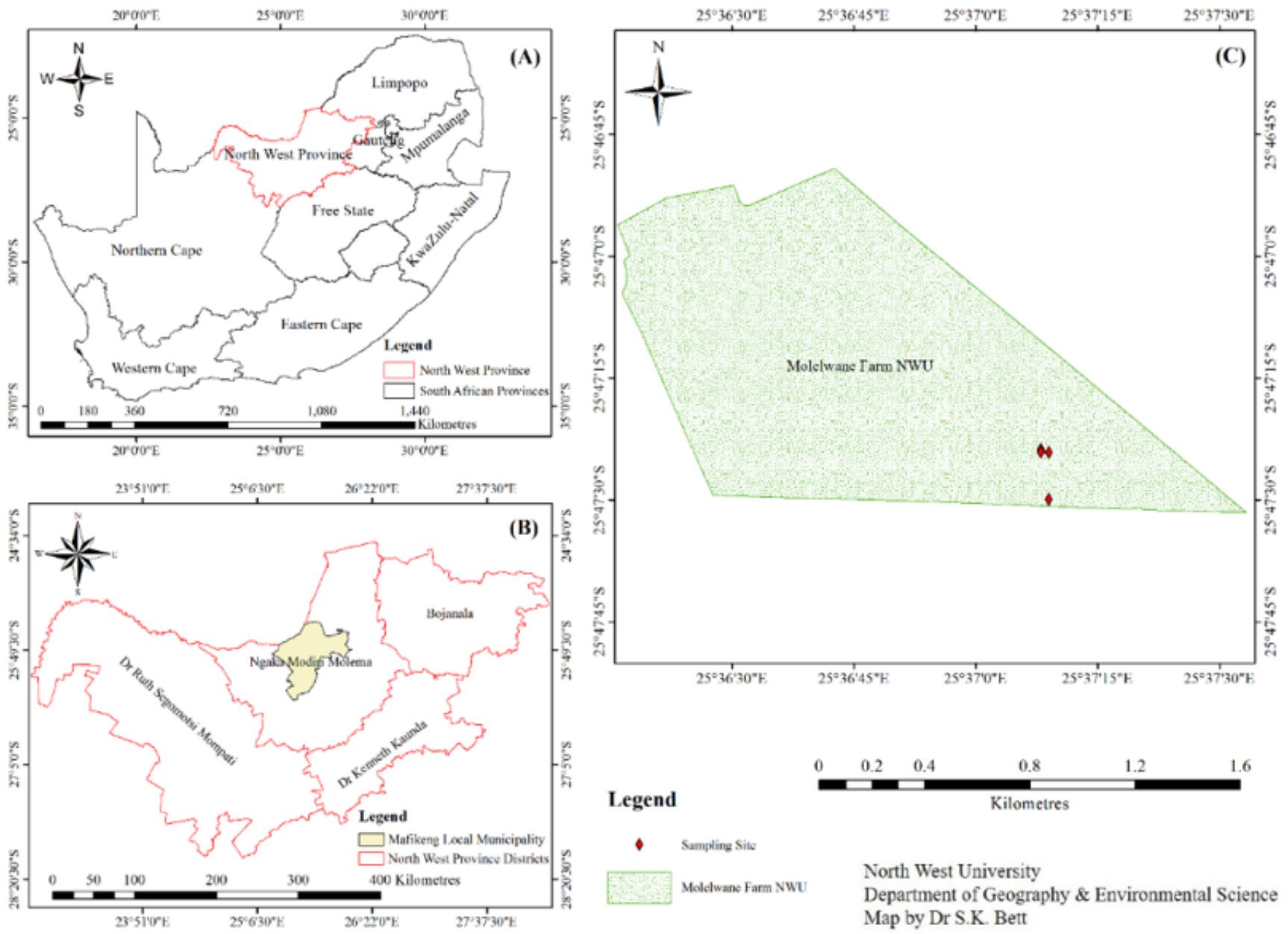

Figure 1

Sketch map of the study area, Molelwane farm, North West Province, South Africa 


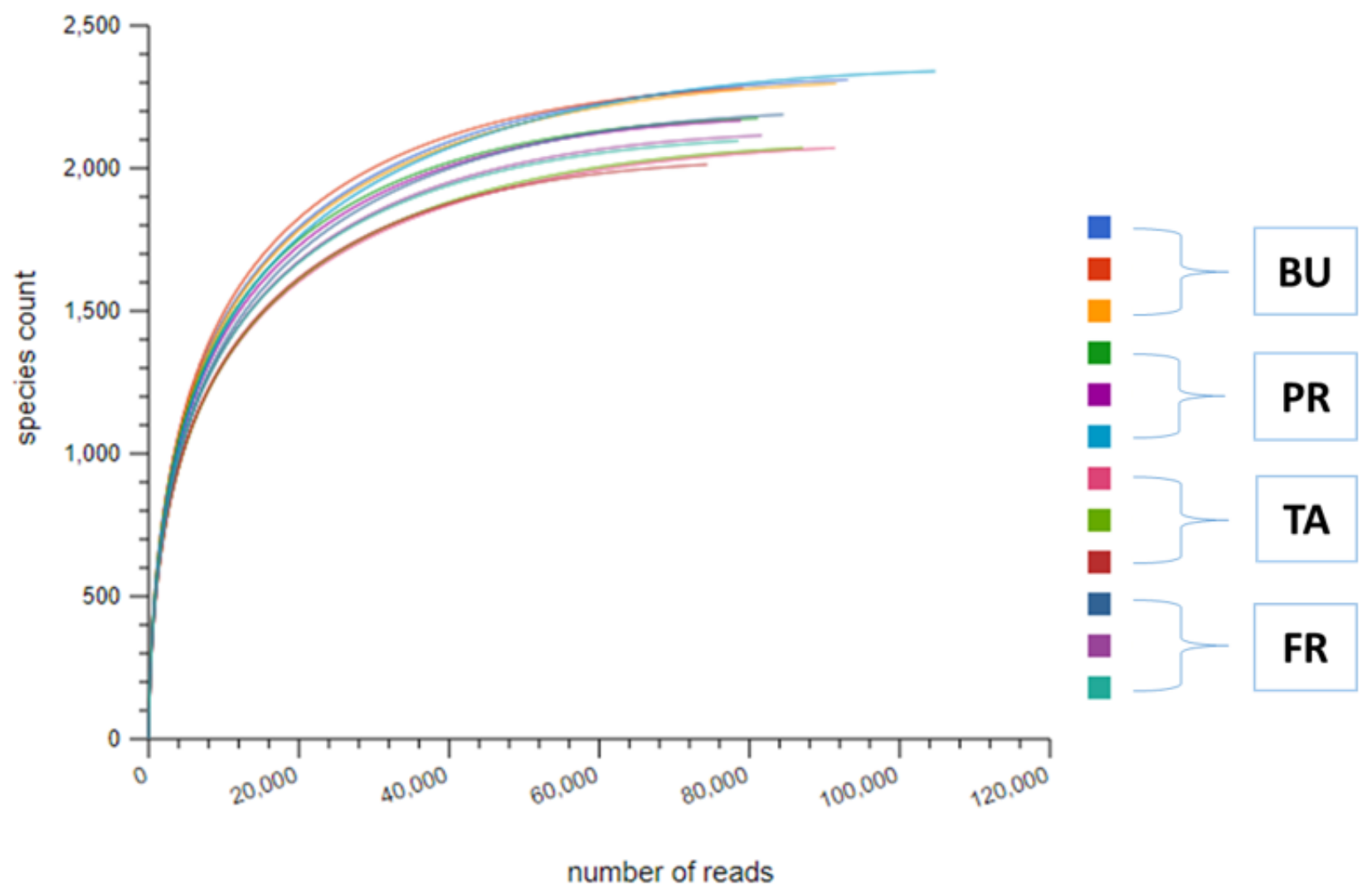

Figure 2

Rarefractive curves showing the richness of species sequences across the different vegetative growth. BU= samples from bulk soil, $\mathrm{PR}=$ samples from pretasseling growth stage, $T A=$ samples from tasseling growth stage, $\mathrm{FR}=$ samples from fruiting growth stage 


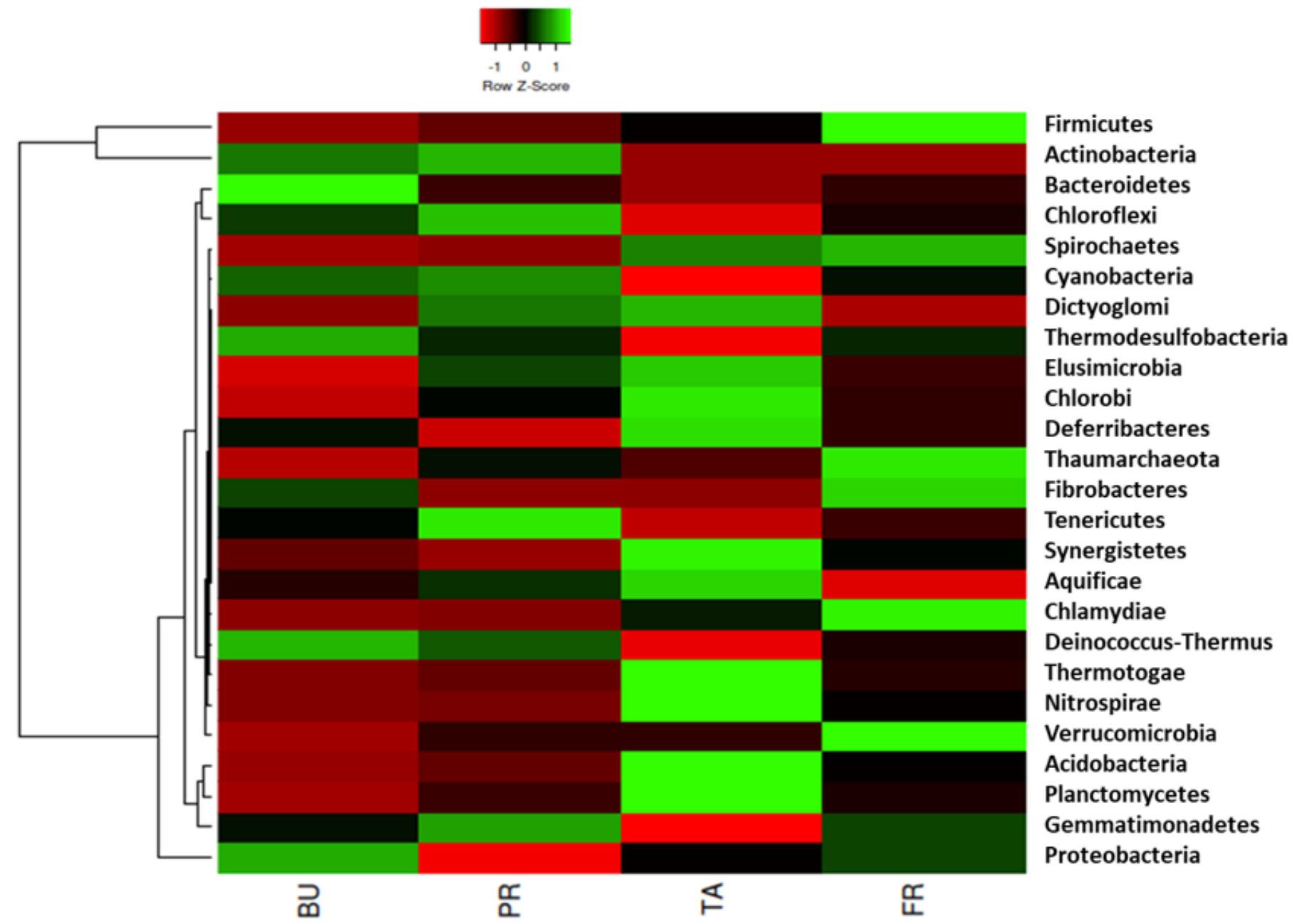

Figure 3

Heatmap showing the relative abundance of Bacteria and Archaea at each growth stage. Z-score with the scale bar show the gradient of colour saturation representing the relative abundance of the organisms. BU= samples from bulk soil, PR= samples from pretasseling growth stage, $T A=$ samples from tasseling growth stage,and $F R=$ samples from fruiting growth stage. 


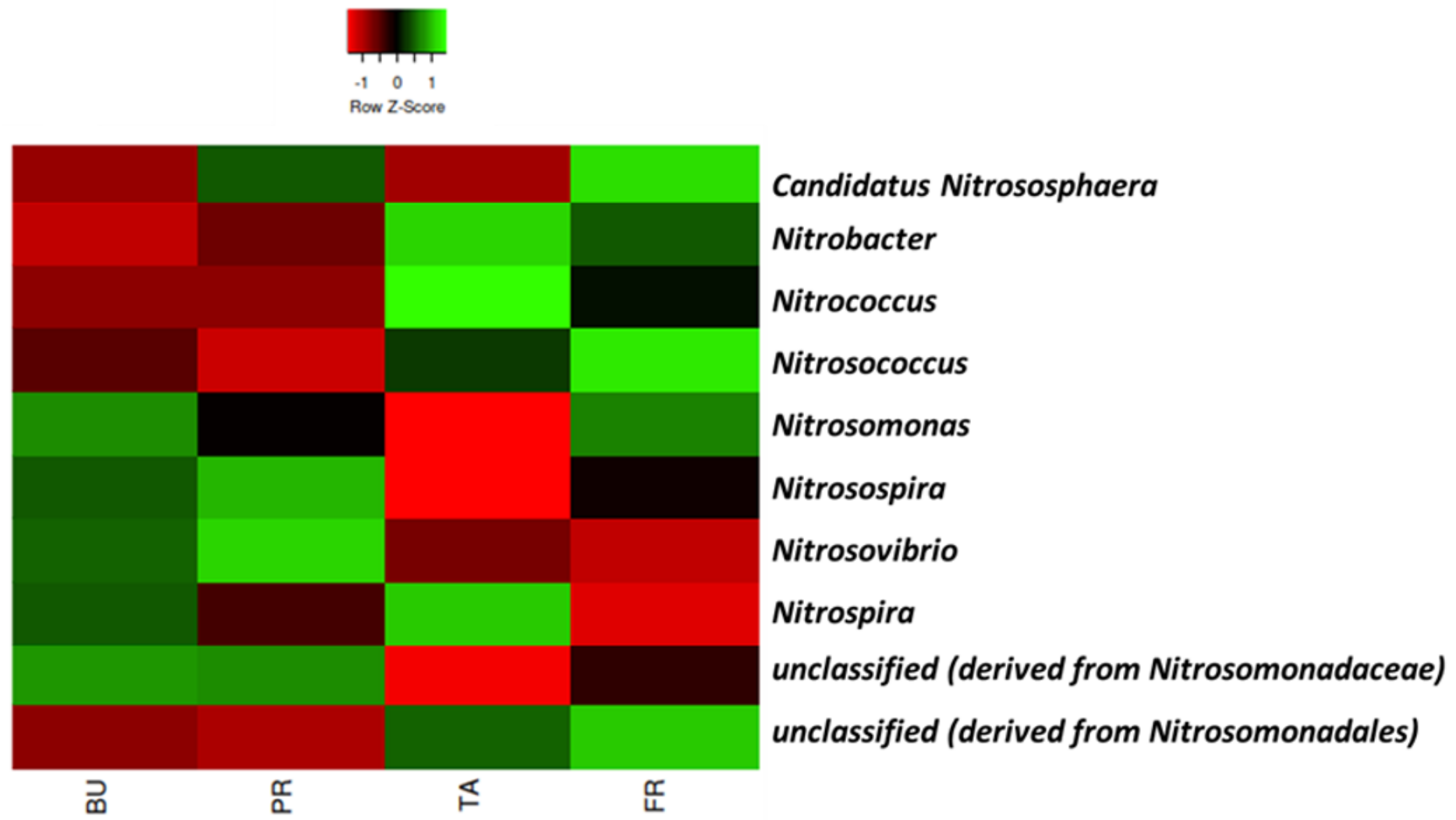

Figure 4

Heatmap showing list and relative abundance of nitrifying bacteria and archaea genera. Z- score with the scale bar shows the gradient of colour saturation representing the relative abundance of the organisms.
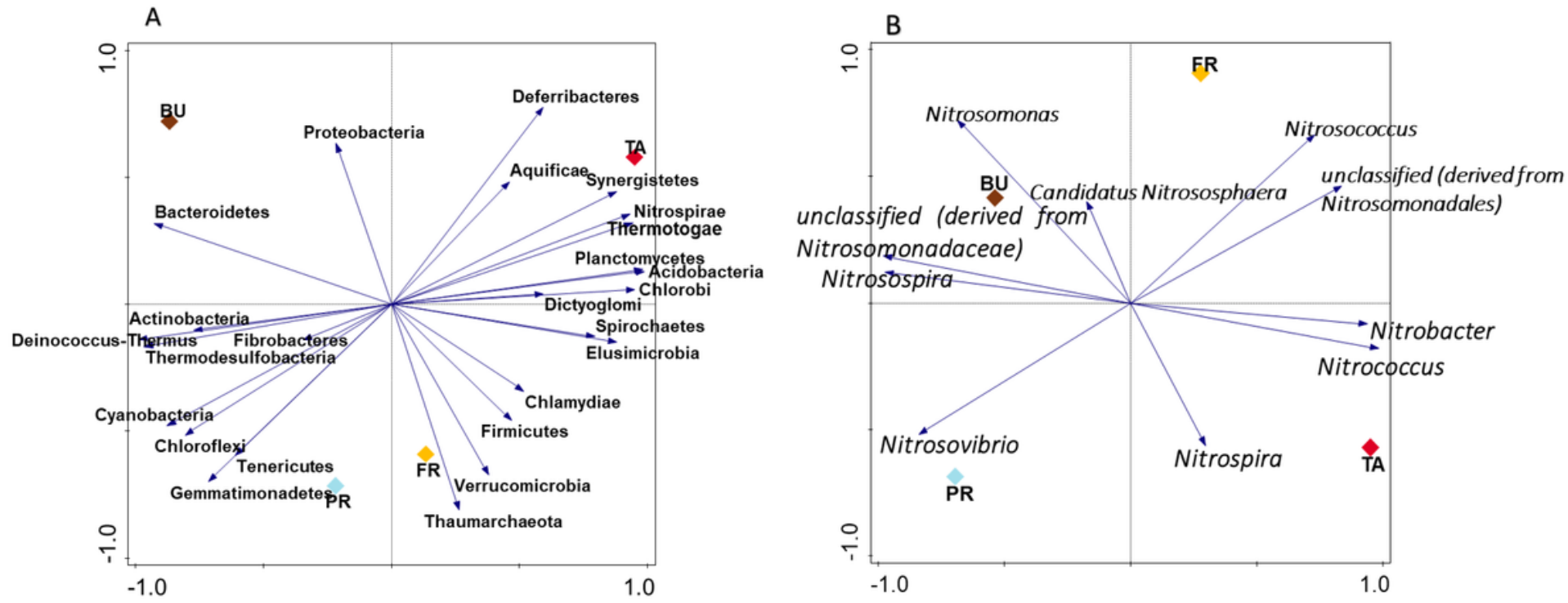

Figure 5

Principal Component analysis (PCA) of nitrifying bacteria and archaea group 16S metagenomics sequence. The resultant vector showed the structural shift and the influence of nitrifying bacteria and archaea. Axis 1 and 2 explained the observed variation based on Euclidean dissimilarity matrix. [A; Phylum level axis 1 (83\%), axis 2 (11\%). B; Genus level axis 1 (69\%), axis 2(21\%)]. 


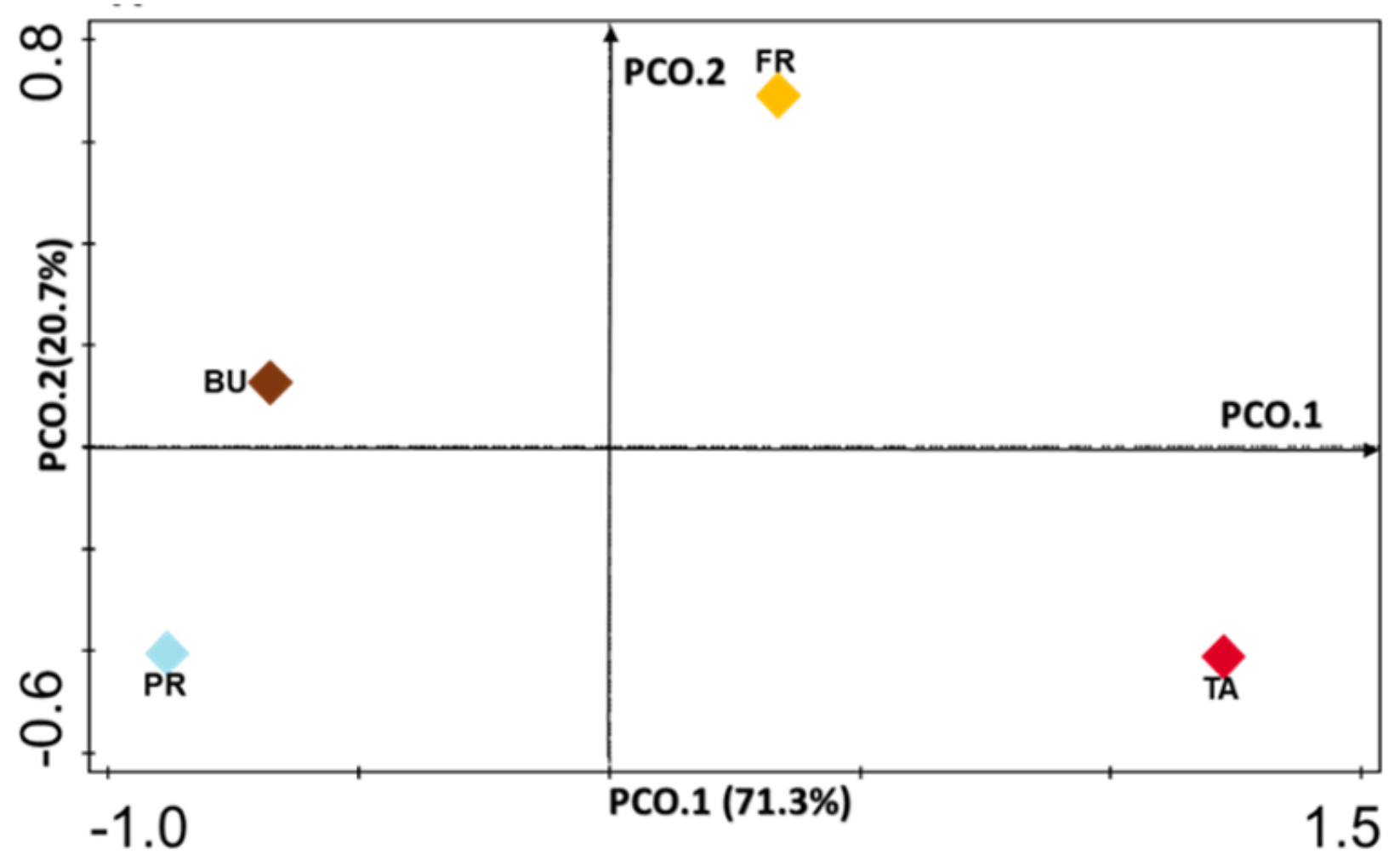

Figure 6

Principal coordinate analysis (PCOA) of nitrifying bacteria and archaea genera across different growth stages. 